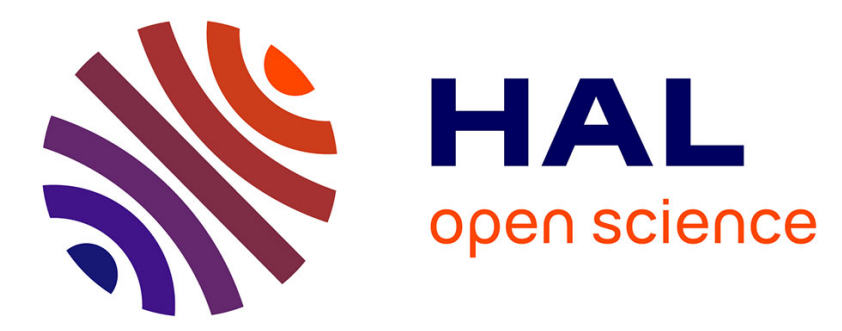

\title{
Prediction of the vibroacoustic response of an electric window-lift gear motor
}

Emmanuel Rigaud, Sarah Diop, Pierre-Henri Cornuault, Benoit Bazin, Emmanuel Grandais-Menant

\section{- To cite this version:}

Emmanuel Rigaud, Sarah Diop, Pierre-Henri Cornuault, Benoit Bazin, Emmanuel Grandais-Menant. Prediction of the vibroacoustic response of an electric window-lift gear motor. CFM 2017 - 23ème Congrès Français de Mécanique, Aug 2017, Lille, France. hal-03465795

\section{HAL Id: hal-03465795 \\ https://hal.science/hal-03465795}

Submitted on 3 Dec 2021

HAL is a multi-disciplinary open access archive for the deposit and dissemination of scientific research documents, whether they are published or not. The documents may come from teaching and research institutions in France or abroad, or from public or private research centers.
L'archive ouverte pluridisciplinaire HAL, est destinée au dépôt et à la diffusion de documents scientifiques de niveau recherche, publiés ou non, émanant des établissements d'enseignement et de recherche français ou étrangers, des laboratoires publics ou privés. 


\title{
Prediction of the vibroacoustic response of an electric window-lift gear motor
}

\author{
E. RIGAUD ${ }^{\mathrm{a}}$, S. DIOP, ${ }^{\mathrm{a}, \mathrm{b}}$, P-H. CORNUAULT ${ }^{\mathrm{c}}$, B. BAZIN ${ }^{\mathrm{b}}$, \\ E. GRANDAIS-MENANT ${ }^{b}$
}

a. LTDS, UMR CNRS 5513, Ecole Centrale de Lyon, Université de Lyon, 69134 Ecully cedex. emmanuel.rigaud@ec-lyon.fr, sarah.diop@ doctorant.ec-lyon.fr

b. INTEVA Products, ZAC, 14220 Esson.

BBazin@intevaproducts.com, EGrandaisMenant@intevaproducts.com

c. Femto-ST, UMR CNRS 6174, Dpt de Mécanique Appliquée, UBFC. 25000 Besançon.pierre-henri.cornuault@ens2m.fr

\begin{abstract}
:
A numerical approach is proposed for analyzing the vibroacoustic behavior of an electric window-lift gear motor and differentiating the different excitation sources. These ones correspond to the normal electromagnetic forces applied to steel stator, the electromagnetic input torque fluctuation, the rotor mechanical imbalance, the worm gear static transmission error and mesh stiffness fluctuations and the gear wheel eccentricity. The computing of the vibroacoustic response is performed using an iterative spectral method. Spectrograms of the dynamic response show components corresponding to the harmonics of the excitation spectra as well as a frequency enrichment generated by the coupling between the mesh stiffness fluctuation and the other driveline excitation sources. Finally, the contributions of the different excitation sources to the the mean square velocity of the radiating surface and the equivalent global dynamic force transmitted to the supporting structure are compared.
\end{abstract}

\section{Résumé :}

Une approche numérique est mise en ouvre pour analyser le comportement vibroacoustique d'un motoréducteur de lève-vitre automobile et comparer le poids respectif des différentes sources d'excitation suivantes : les pressions de Maxwell qui s'exercent sur le stator et les fluctuations du couple moteur d'origine électromagnétique, le balourd du rotor, les fluctuations de l'erreur statique de transmission et de la raideur d'engrènement générées par le réducteur à roue/vis sans fin et l'excentricité de la roue. Le calcul de la réponse vibroacoustique est réalisé à l'aide d'une méthode spectrale et itérative. Les spectrogrammes sont caractérisés par les harmoniques générées par les excitations, ainsi que par un enrichissement fréquentiel lié au couplage entre la fluctuation de la raideur d'engrènement et les autres sources d'excitation. Finalement, on compare les contributions respectives des différentes sources à la vitesse quadratique du carter et aux efforts transmis à la structure d'accueil.

Keywords: DC motor, electromagnetic forces, worm gear, mechanical imbalance, eccentricity, multiphysics coupling 


\section{Introduction}

The aim of this paper is to analyze the vibroacoustic behavior of an electric window-lift gear motor for automotive vehicle which equips each door of newer automotive vehicles. It consists of a DC motor and a worm gear (cf. Figure 1). Its housing is made of a steel stator which supports diametrically opposed ferrites generating a permanent magnetic field, and a plastic part which supports the cage containing two metal-graphitic brushes supplying electrical power to the rotor. The housing is attached to the door of the automotive vehicle at three fixation points. The rotor is guided by a front, a center and a rear journal bearings. It consists of a shaft on which coils are wound (number of coils: $N=10$ ) and connected to the $N$ blades of a rotating commutator. When the current flows in the coils positioned within the magnetic field, normal (Maxwell) and tangential (Lorentz) electromagnetic forces are created. The last ones generate the input torque allowing the rotating motion of the rotor. A worm is machined in the steel rotor, between the front and the center journal bearings. It is designed such as the mesh frequency $f_{m}$ is equal to the rotor frequency $f_{r}$. It meshes with a polyoxymethylene (POM) helical gear wheel in order to reduce the rotation speed and increase the output torque (number of gear teeth: $Z=73$, worm gear ratio 1:73). The axial component of the mesh force is taken up by two curved pads acting as axial stops and mounted at each of the rotor ends. Finally, the gear wheel goes up and down the window, depending on the direction of rotation of the window-lift motor, via a mechanical clutch connected to a drum and cables mechanism. The standard gear motor operating conditions correspond to an input speed equal to $6000 \mathrm{rpm}$ and an output torque equal to 3 N.m.
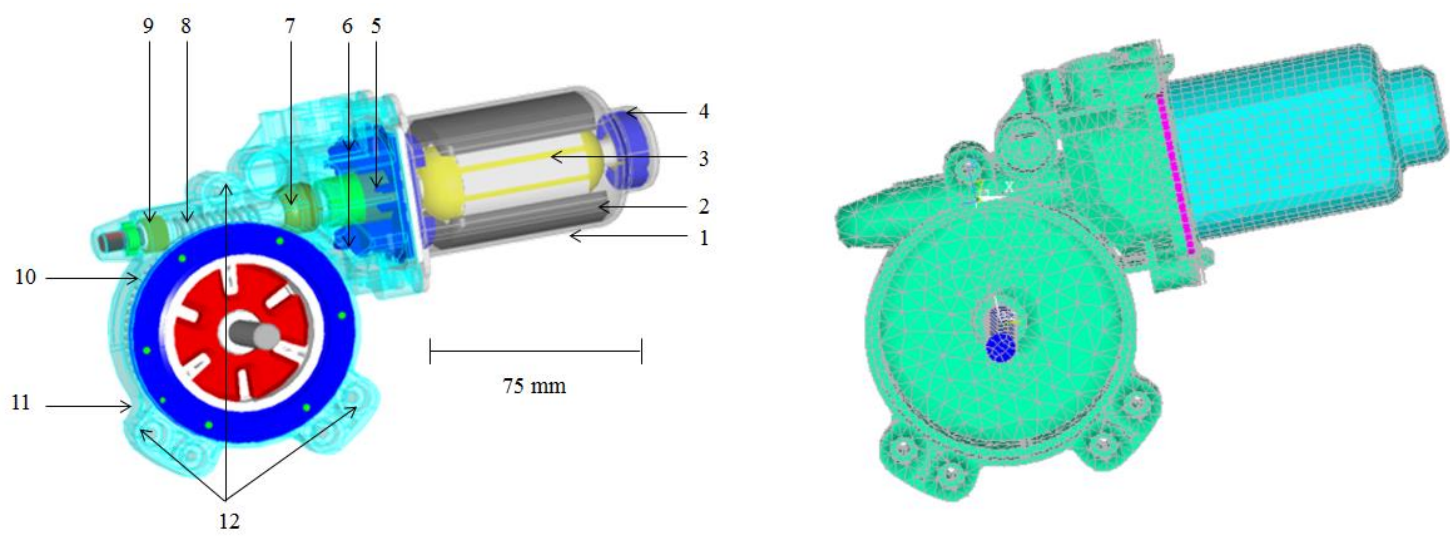

Figure 1: Window-lift gear motor. Steel stator (1) - permanent magnet (2) - coils (3) - rear (4), center (7) and front bearings (9) - commutator (5) - carbon brushes (6) - worm (8) - gear wheel (10) - plastic part (11) - fixation points (12).

Figure 2: Meshing of the plastic part and the steel stator.

This article presents a numerical approach for differentiating and prioritizing the different excitation sources of the window-lift gear motor. The first part describes the modelling of the excitation sources. The second part describes the dynamic modelling and the iterative spectral method used for computing the vibroacoustic response of the gear motor. The frequency content and the amplitude of the responses generated by the excitation sources are compared to assess their contribution to the vibroacoustic behavior of the gear motor.

\section{Excitation sources}

Under operating conditions, various mechanical and electromagnetic phenomena generate excitation of the window-lift gear motor. They induce vibration and noise radiated by the gear motor housing itself, 
as well as dynamical forces transmitted to the door which can also radiate inside the automotive interior. The following excitation sources are considered.

\section{Electromagnetic forces}

The fluctuation of the input electrical current at the contact between commutator and brushes and the periodic motion of the rotating coils through the permanent magnetic field generate periodic fluctuation of normal and tangential electromagnetic forces, at the blade or coil passage frequency $\left(10 f_{r}\right)$. The fluctuation of the electromagnetic forces is computed using the simulation software Maxwell ${ }^{\odot}$. A 2D finite element modelling of the coils and their armature, the ferrites and the air gap is performed in order to evaluate the electromagnetic field in steady state operating condition under the following assumptions. The 10 coils have the same resistance and show no asymmetry. The rotor motion is perfectly centered with respect to the magnetic field generated by the ferrites. There is no friction and no iron loss due to the hysteresis of the ferromagnetic material. The thickness of the stator is oversized. The line resistance is $0.15 \mathrm{Ohms}$ and the applied voltage is $14.5 \mathrm{~V}$. The numerical simulation performed allows computation of the spatial distribution of the normal and tangential magnetic fields $B_{n}$ and $B_{t}$ in the air gap (between 0 and $360^{\circ}$ ), for different successive rotor positions describing 1/10th of a rotation. The instantaneous surface densities of the normal and tangential forces $\sigma_{n}$ and $\sigma_{t}$ are then estimated from the vacuum permeability $\mu_{0}$ and the preceding magnetic fields $B_{n}$ and $B_{t}$ :

$$
\sigma_{n}(t)=\frac{B_{n}(t)^{2}-B_{t}(t)^{2}}{2 \mu_{0}} \quad \sigma_{t}(t)=\frac{B_{n}(t) B_{t}(t)}{\mu_{0}}
$$

On the one hand, time and space evolution of the normal electromagnetic forces is projected onto the 3D steel stator structural finite element model. On the other hand, the tangential electromagnetic forces generate the input torque $T(t)$ evaluated from the following equation:

$$
T(t)=R \int \sigma_{t}(t) d S
$$

with $R$ and $S$ the coils radius and external surface.

\section{Mechanical imbalance}

The rotor is balanced at the output of the production line in order to obtain a final imbalance lower than a limit value $m r_{\max }$ defined in the specifications. Nevertheless, the residual imbalance induced by the asymmetry of the rotor is responsible for an excitation modelled by a rotating force at the center of the coils whose frequency corresponds to the rotor frequency $f_{r}$ and whose amplitude varies with the rotation speed of the rotor [1]:

$$
F_{y}=m r \omega^{2} \cos (\omega t) \quad F_{z}=m r \omega^{2} \sin (\omega t)
$$

\section{Static transmission error STE(t) and mesh stiffness fluctuations $k(t)$ of the worm gear}

The meshing between the worm and the gear wheel generates an excitation corresponding to the static transmission error (STE) fluctuation [2] and resulting from tooth deflections and manufacturing errors. STE is periodic at the mesh frequency $\left(f_{m}=f_{r}\right)$. Its time evolution is evaluated from the resolution of the equation describing the static contact between the gear teeth (Rigaud et al. [3]) for a given load $F$ applied to the worm gear contact, and for a set of successive positions $\theta$ of the driving wheel. The gear mesh stiffness fluctuation associated with STE generates a parametric excitation of the mechanical system [4]. For each of the successive positions $\theta$ of the driving wheel, the mesh stiffness is defined as the derivative of the transmitted load $F$ relative to STE:

$$
k(\theta)=\frac{\partial F}{\partial \delta(\theta)}
$$

Figure 3 displays the amplitude spectrum of the input torque, STE and mesh stiffness fluctuations.

\section{Gear wheel eccentricity}

Manufacturing and mounting errors of the gear wheel are responsible for an eccentricity defect. This generates an additional component to STE at a frequency corresponding to the rotation frequency of the wheel $\left(f_{r} / 73\right)$. The amplitude of the component corresponds to the eccentricity fault $(40 \mu \mathrm{m})$. 

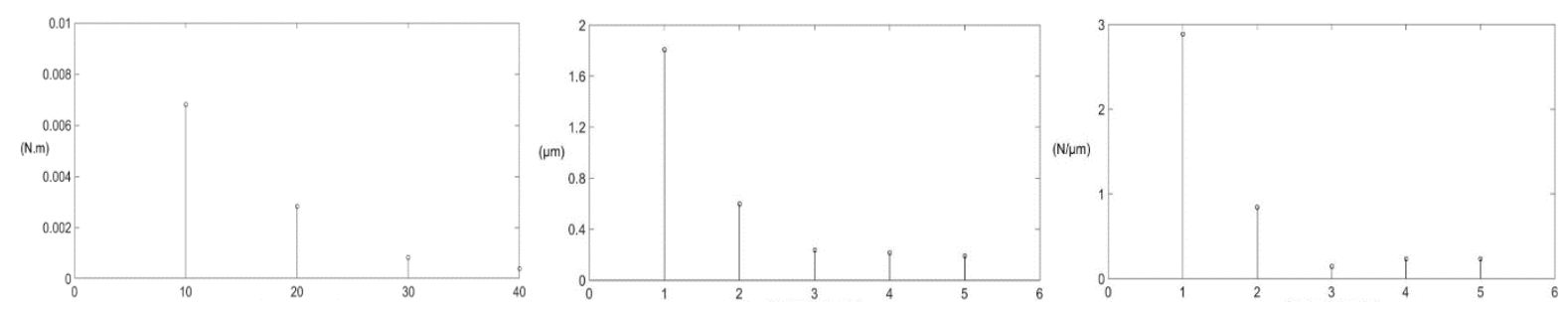

Figure 3: Amplitude spectrum of the input torque $\mathrm{T}(\mathrm{t})$, the static transmission error $\mathrm{STE}(\mathrm{t})$ and the mesh stiffness fluctuation $\mathrm{k}(\mathrm{t})$.

\section{Computing of the gear motor dynamic response}

The gear motor is modelled using the finite element method. Figure 2 displays the meshing of the housing. The rotor is discretized using beam elements. The additional components (coils, collector) and the gear wheel are modelled by added mass and inertia elements. Parameters of the finite element model have been adjusted for each of the sub-assemblies (steel stator, plastic part and rotor) using an experimental modal analysis under free-boundary conditions. Differences between experimental and numerical first natural frequencies is less than $2 \%$. The elastic coupling between the rotor and the housing is modelled using radial stiffness elements for the three journal bearings (front, center and rear) and axial stiffness elements for the two axial stops (front and rear). The meshing between the worm and the gear wheel is modelled using a 12x12 stiffness matrix which couples the 6 degrees of freedom of the wheel to the 6 degrees of freedom of the rotor node corresponding to the worm [4]. This matrix is defined from the geometrical characteristics of the worm gear and the mesh stiffness mean value.

The stationary dynamic response of the discretized gear motor is described by a parametric equation of motion with periodic coefficients which can be written in the following matrix form:

$$
M_{E F} \ddot{x}+C \dot{x}+K_{E F} x+k(t) R R^{T} x=k(t) R R^{T} x_{s}(t)+F(t)
$$

$M_{E F}$ and $K_{E F}$ are the mass and stiffness matrices provided by the finite element method. The elastic coupling between the worm and the gear wheel is introduced by the term $k(t)$ which corresponds to the mesh stiffness fluctuation. Vector $R$ is associated with the worm gear geometry and $C$ is the matrix taking account of the dissipation terms introduced using an equivalent viscous modal damping rate. $x_{s}(t)$ is the static transmission error and $F(t)$ constitutes the generalized forces associated with the other excitations. Parametric equation of motion is solved using a spectral and iterative method which allows the computing of the stationary dynamic response for large systems of periodic differential equations with minimal computation times [5].

\section{$4 \quad$ Results and discussion}

The following indicators are of particular interest. First, the spatial average of the mean square velocity of the radiating surface $\left\langle\overline{V^{2}(\omega)}\right\rangle_{s}$ is deduced from the normal vibratory response at each degree of freedom of the housing. It allows estimation of the acoustic power $\Pi_{a c}(\omega)$ radiated from the gear motor assuming a unit radiation factor:

$$
\Pi_{a c}(\omega)=\rho_{0} c_{0} S \sigma_{\text {rad }}(\omega)<\overline{V^{2}(\omega)}>_{s}
$$

with $\rho_{0}$ is the air density, $c_{0}$ is the velocity of sound, $S$ is the radiating surface, $\sigma_{\mathrm{rad}}(\omega)$ is the radiation factor and $\left\langle\overline{V^{2}(\omega)}\right\rangle_{S}$ is the spatial average of the mean square velocity of the radiating surface.

Second, an equivalent global dynamic force $F_{t}$ transmitted to the supporting structure by the gear motor is introduced from the set of reaction forces $F_{x}, F_{y}$ and $F_{z}$ at the fixation points. $F_{t}$ can be at the origin 
of the acoustic radiation of the vehicle door and therefore has a direct impact on the noise perceived inside the passenger compartment.

$$
F_{t}=\sqrt{F_{x}^{2}+F_{y}^{2}+F_{z}^{2}}
$$

The level (in $\mathrm{dB}$ ) of the spatial average of the mean square velocity $L_{S V^{2}}(d B)$ and the equivalent global dynamic transmitted force $L_{F t}(d B)$ are calculated as follows:

$$
L_{S V^{2}}(d B)=10 \log \left(\frac{\rho_{0} c_{0} S<\overline{V^{2}(\omega)}>_{S}}{\Pi_{\text {ref }}}\right) \quad L_{F t}(d B)=10 \log \left(\frac{F_{t}}{F_{\text {ref }}}\right)
$$

with reference values $F_{\text {ref }}=1 \mathrm{~N}$ and $\Pi_{\text {ref }}=10^{-12}$ Watts.

Figure 4 displays the evolution of the root mean square value of the dynamic responses versus operating regime. Figures 5 and 6 display the spectrograms of the equivalent global dynamic transmitted force $L_{F t}(d B)$ and the spatial average of the mean square velocity $L_{S V^{2}}(d B)$ for operating regimes in the range $[0-8500 \mathrm{rpm}]$. The amplitude spectrum of the dynamic responses (in physical units) for the standard operating regime $(6000 \mathrm{rpm})$ is also displayed. The following excitations are considered: normal electromagnetic forces applied to the steel stator (a-f), electromagnetic input torque fluctuation (b-g), mechanical imbalance (c-h), static transmission error (d-i), gear wheel eccentricity (e-j).

The spectrograms of the dynamic response show components corresponding to the harmonics of the excitation spectra considered: $\mathrm{H}_{1 / 73}$ for the gear wheel eccentricity, $\mathrm{H}_{1}$ for the mechanical imbalance, $\mathrm{H}_{1}, \mathrm{H}_{2}, \mathrm{H}_{3}$, etc. for the static transmission error, $\mathrm{H}_{10}, \mathrm{H}_{20}, \mathrm{H}_{30}$ for the electromagnetic normal forces and input torque fluctuation. The parametric equation of motion leads to a coupling between the mesh stiffness fluctuation and the other excitation sources which generates a frequency enrichment of the dynamic response. The coupling with the gear wheel eccentricity leads to emergence of lateral components around harmonics of the mesh frequency $\left(\mathrm{H}_{\mathrm{i}} \pm 1 / 73\right)$. The coupling with mechanical imbalance is negligible and does not generate any significant new component. The coupling with the static transmission error results in a change in the amplitude of the components multiple of the mesh frequency $\left(\mathrm{H}_{1}, \mathrm{H}_{2}\right.$, etc.). Finally, the coupling with the electromagnetic input torque leads to emergence of numerous lateral components $\left(\mathrm{H}_{10 \times \mathrm{x} \pm 1}, \mathrm{H}_{10 \times \mathrm{i} \pm 2}\right.$, etc.). They have usually a smaller amplitude than the main components. They are thus not very involved in the overall amplitude of the vibroacoustic response. Nevertheless, they have a significant impact on its nature and on the observer's feelings. They can be at the origin of modulation phenomena which noticeably modify the quality of the noise radiated directly by the gear motor or indirectly by the supporting structure to which forces are transmitted at the fixation points.

Some amplification peaks of the dynamic response are observed. They correspond to the resonant excitation of some natural modes of the gear motor. For example, considering the electromagnetic normal forces, harmonic $\mathrm{H}_{10}$ leads to a resonant excitation of the $4^{\text {th }}$ mode $(640 \mathrm{~Hz}$, twist deformation of the plastic part of the housing) for the regime $3860 \mathrm{rpm}$. No significant amplification peaks were observed in the range of standard stationary operating speeds $(6000-8000 \mathrm{rpm})$. On the other hand, considering mechanical imbalance, harmonic $\mathrm{H}_{1}$ leads to a resonant excitation of the $2^{\text {nd }}$ mode $(95 \mathrm{~Hz}$, deformation of the housing mainly localized at the steel stator) for the regime $5800 \mathrm{rpm}$ in the vicinity of the standard stationary operating regime of the gear motor.

Figure 4 a displays the equivalent global dynamic force $F_{t}$ transmitted to the supporting structure for the different excitation sources. In the absence of gear wheel eccentricity fault, $F_{t}$ is mainly generated by the static transmission error between 0 and $3000 \mathrm{rpm}$, by electromagnetic normal forces between 3500 and $4500 \mathrm{rpm}$ and by the rotor mechanical imbalance around $5800 \mathrm{rpm}$, due to the resonant excitation of the $2^{\text {nd }}$ mode $(95 \mathrm{~Hz})$. In the vicinity of the standard stationary operating regime $(6000-8000 \mathrm{rpm})$, the weight of the electromagnetic normal forces, the rotor mechanical imbalance and the worm gear static transmission error is of the same order of magnitude. The effective value for the equivalent global 
dynamic force is $F_{t}=5 \mathrm{~N}\left(L_{F t}=5.3 \mathrm{~dB}\right)$. The contribution of the engine torque fluctuation is much lower than the other contributions throughout the operating range, despite the spectral enrichment generated by the coupling with the mesh stiffness fluctuation. Simulations performed show that the tangential and the normal forces are of the same order of magnitude. These results are in good agreement with the experimental measurements performed when the gear wheel rotation frequency is filtered. Taking into account the gear wheel eccentricity generates an added contribution to $F_{t}$ at very low frequency $(\mathrm{H} 1 / 73)$. Its effective value is $F_{t}=9.3 \mathrm{~N}\left(L_{F t}=9.7 \mathrm{~dB}\right)$. This result is also in good agreement with the experimental measurements.

Figure $4 \mathrm{~b}$ displays the spatial averages of the mean square velocity of the radiating surface $\left\langle\overline{V^{2}(\omega)}\right\rangle_{S}$ for the different excitation sources. $\left\langle\overline{V^{2}(\omega)}\right\rangle_{S}$ is mainly generated by the electromagnetic normal forces between 0 and $4500 \mathrm{rpm}$ and by the rotor mechanical imbalance above $4500 \mathrm{rpm}$, corresponding to the standard operating regime. Assuming a unit radiation factor, $\left\langle\overline{V^{2}(\omega)}\right\rangle_{S}$ corresponds to a maximum radiated sound power level equal to $74 \mathrm{~dB}$ at $5800 \mathrm{rpm}$. The mean square velocity observed at the steel stator surface is higher than that observed at the plastic part of the housing, whether it is generated by electromagnetic normal forces or by mechanical imbalance. It reaches $1 \mathrm{~mm}^{2} / \mathrm{s}^{2}$ for the regime corresponding to a resonant excitation of the $2^{\text {nd }}$ mode $(95 \mathrm{~Hz})$ by the mechanical imbalance.

The spatial average of the mean square velocity generated by the static transmission error is of a secondary level. The ones generated by the input torque fluctuation and by the gear wheel eccentricity fault are much lower than the other contributions throughout the operating regime range $(-30 \mathrm{~dB}$ compared to that generated by the electromagnetic normal forces and mechanical imbalance).

It is observed that the imbalance-induced response is located at low frequency $\left(\mathrm{H}_{1}, 0-133 \mathrm{~Hz}\right)$, whereas that generated by the static transmission error $\left(\mathrm{H}_{1}-\mathrm{H}_{5}, 0-666 \mathrm{~Hz}\right)$ and by the electromagnetic normal forces $\left(\mathrm{H}_{10}, \mathrm{H}_{20}, \mathrm{H}_{30}, 0-4000 \mathrm{~Hz}\right)$ are located at higher frequencies. A weighting A similar to that used in acoustics (IEC 61672-1 standard) is introduced to take account of the auditory sensitivity of the observer for each frequency band. Conclusions obtained are different (see figure 8c): the spatial average of the mean square velocity are mainly generated by the electromagnetic normal forces between 0 and $5500 \mathrm{rpm}$. Assuming a unit radiation factor, the corresponding maximum radiated sound power level is equal to $63 \mathrm{dBA}$ at $3800 \mathrm{rpm}$. Beyond $5500 \mathrm{rpm}$, the weight of the electromagnetic normal forces, the rotor mechanical imbalance and the worm gear static transmission error is of the same order of magnitude. The effective value for the spatial average of the mean square velocity corresponds to a radiated sound power level between $53 \mathrm{dBA}$ and $56 \mathrm{dBA}$. This result is in good agreement with the experimental measurements.

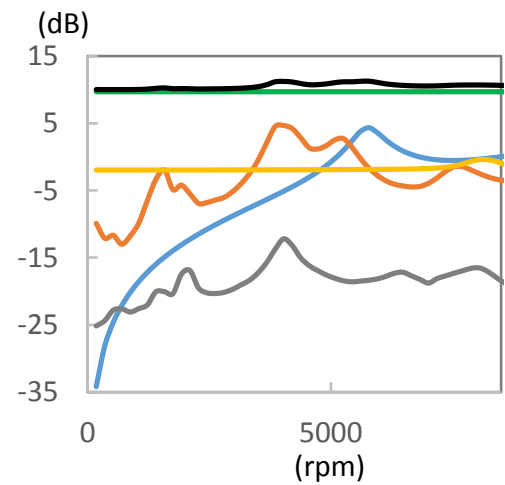

(a) RMS value of $L_{F t}(d B)$.

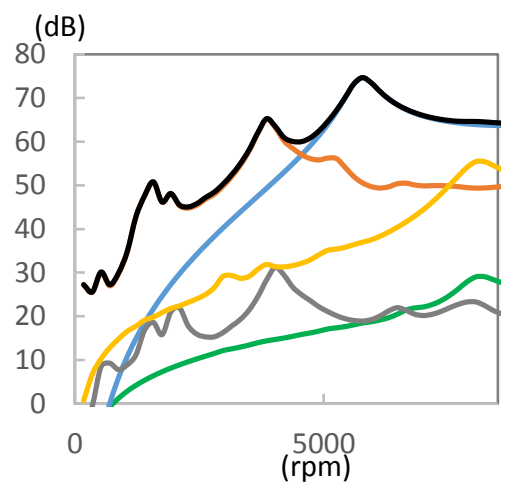

(b) $R M S$ value of $L_{S V^{2}}(d B)$.

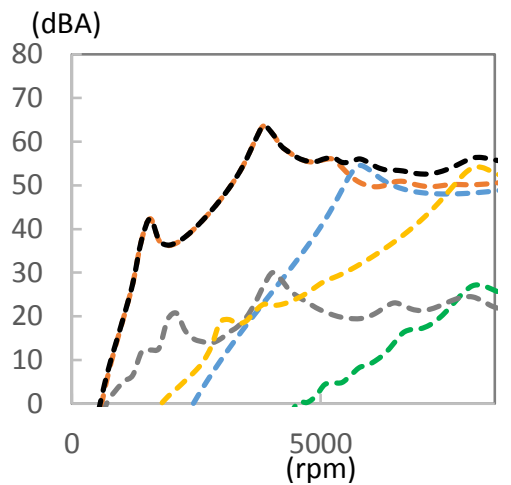

(c) RMS value of $L_{S V^{2}}(d B A)$.

Figure 4: RMS value of the dynamic response versus operating regime. Excitations considered: normal electromagnetic forces, electromagnetic input torque fluctuation, mechanical imbalance, static transmission error, gear wheel eccentricity, overall response. 

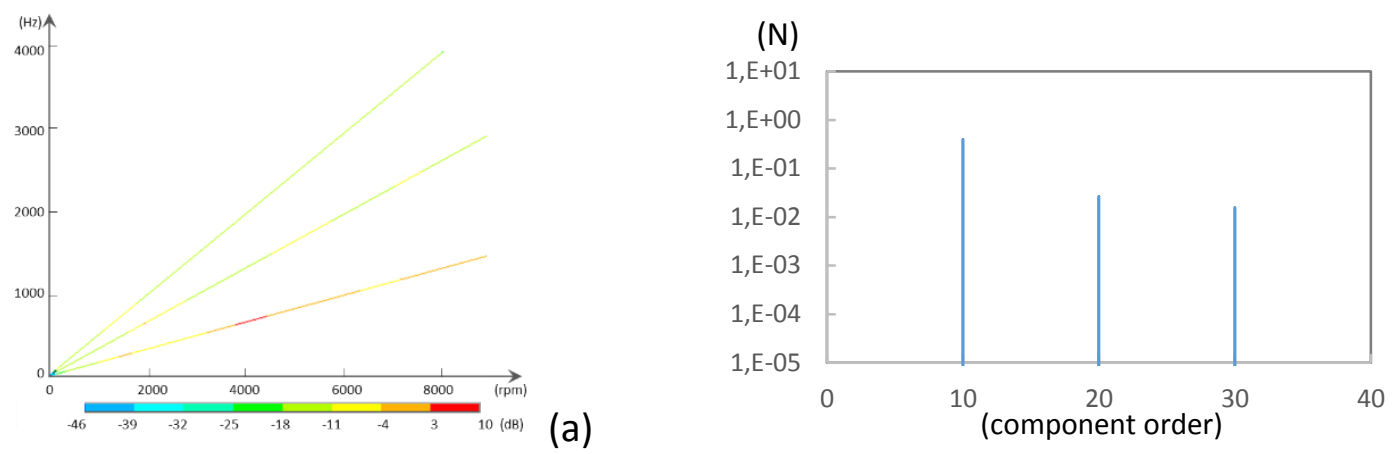

(f)
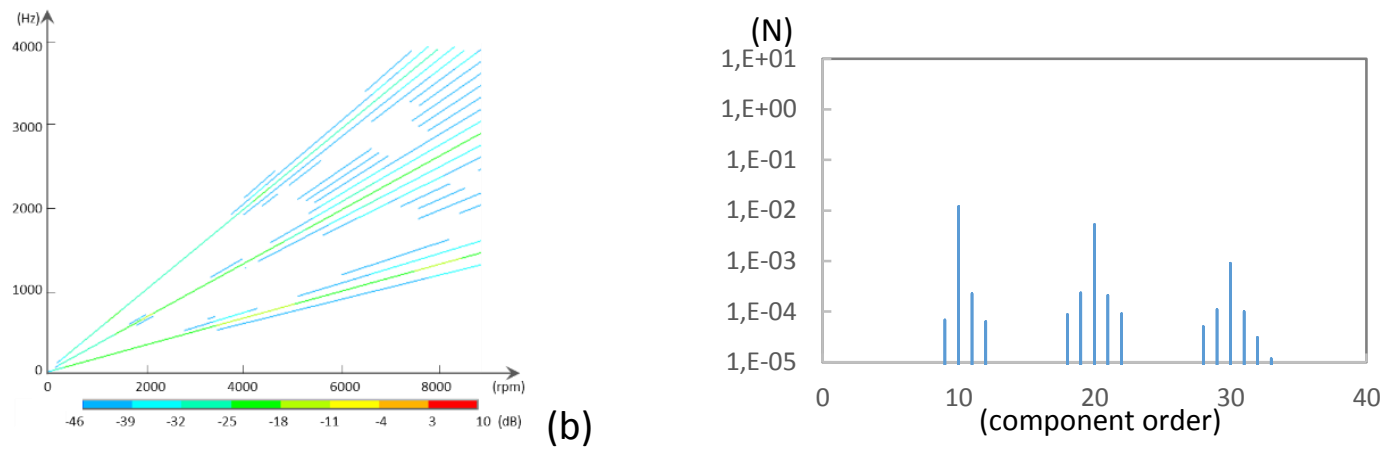

(g)
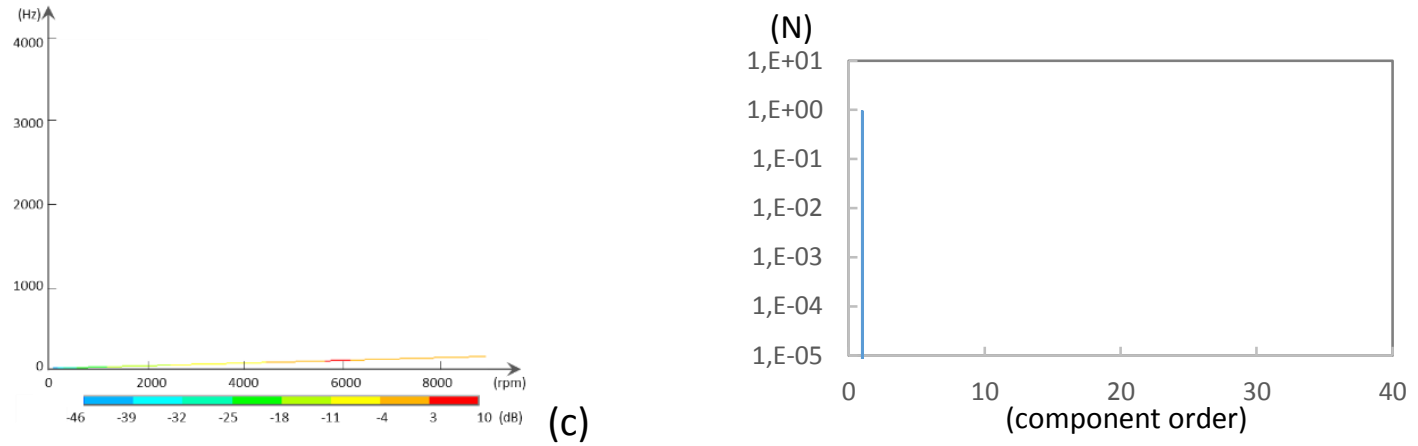

(h)
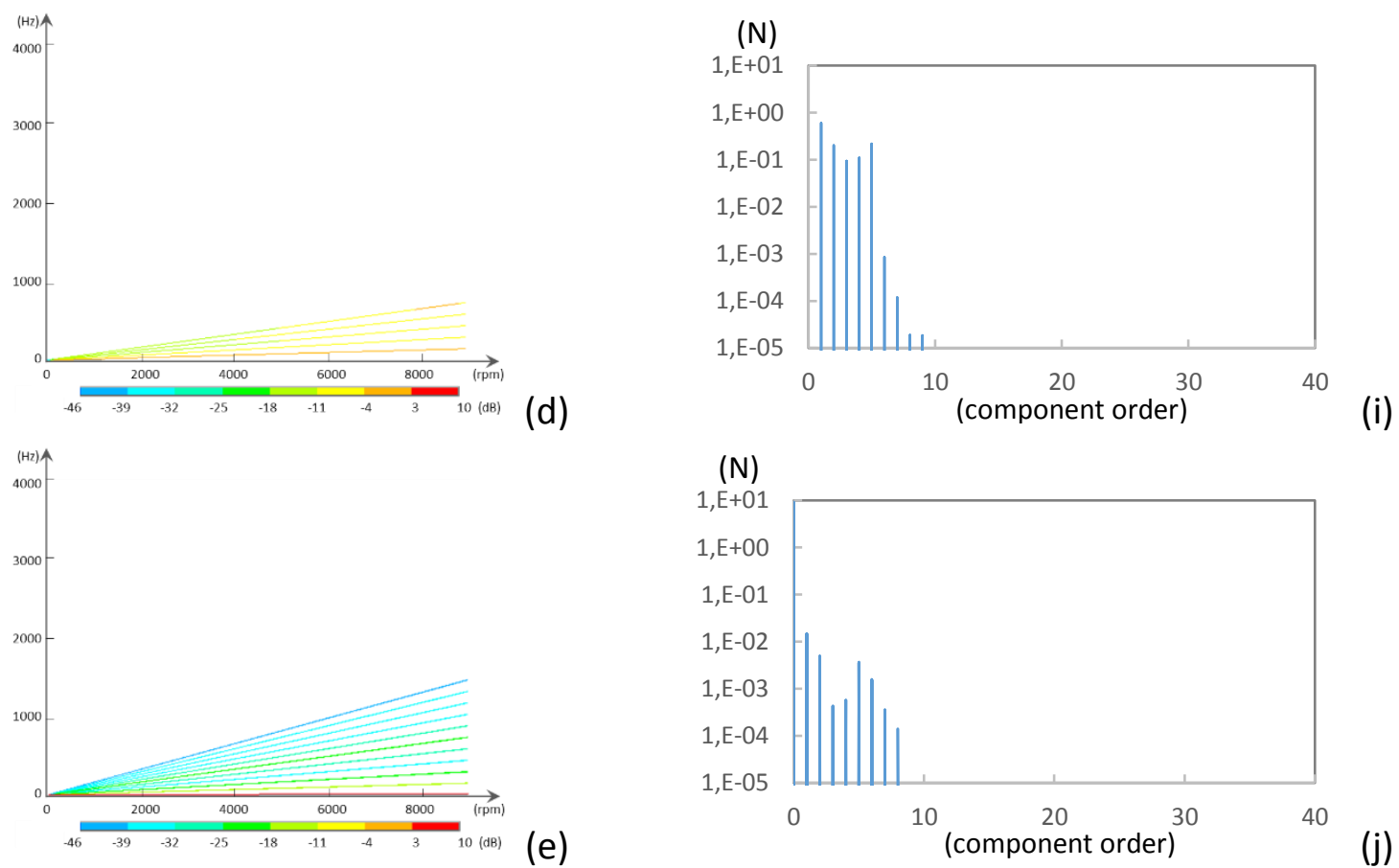

(N)

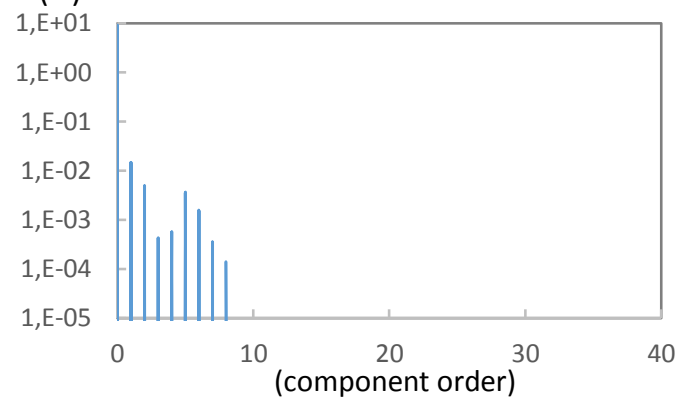

(j)

Figure 5: Spectrograms of the dynamic transmitted force $L_{F t}(d B)$ in the range [0 - $8500 \mathrm{rpm}$ ] Amplitude spectra of $F_{t}(N)$ for the standard operating regime $(6000 \mathrm{rpm})$. 

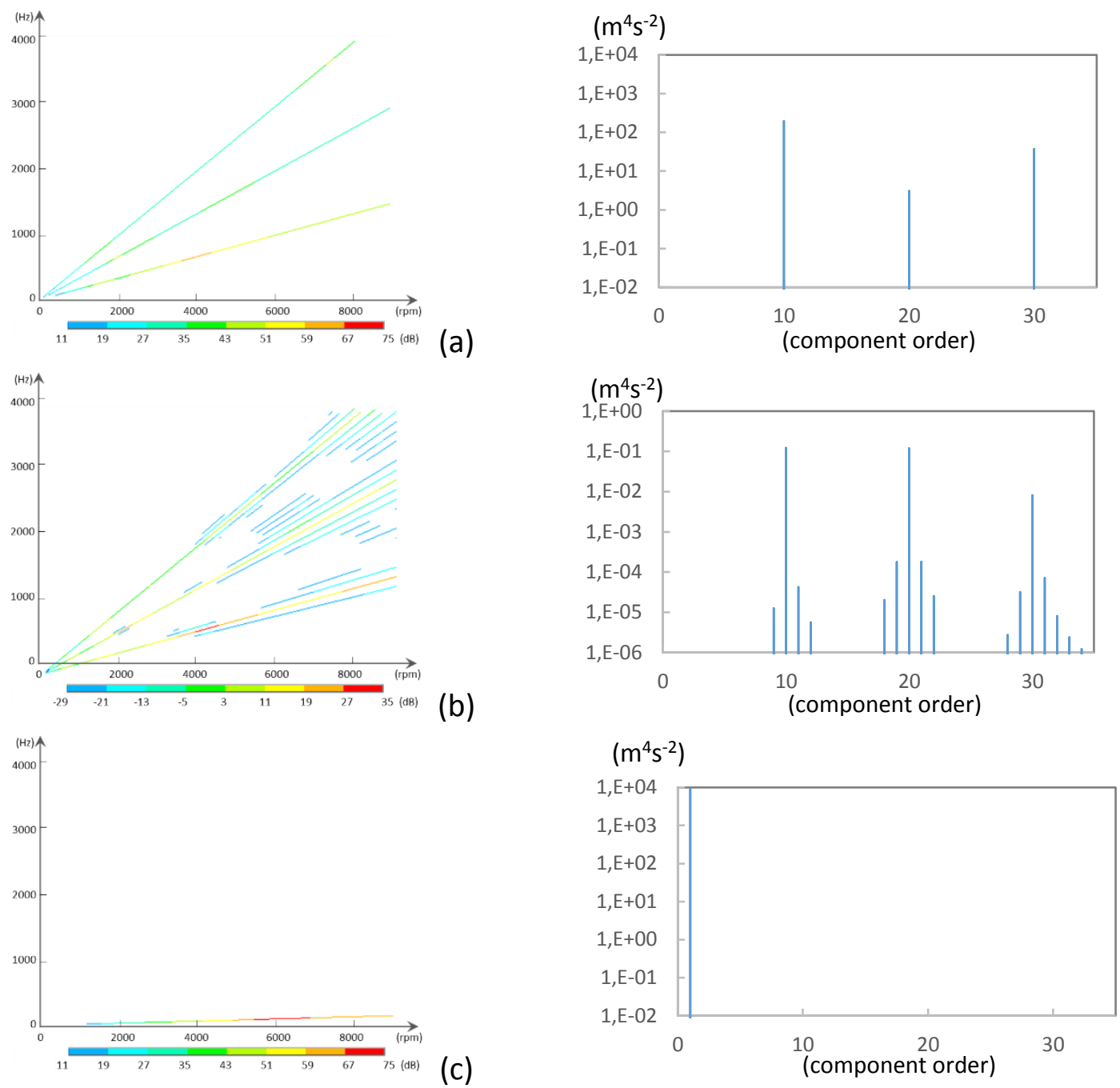

(g)

(c)

(h)

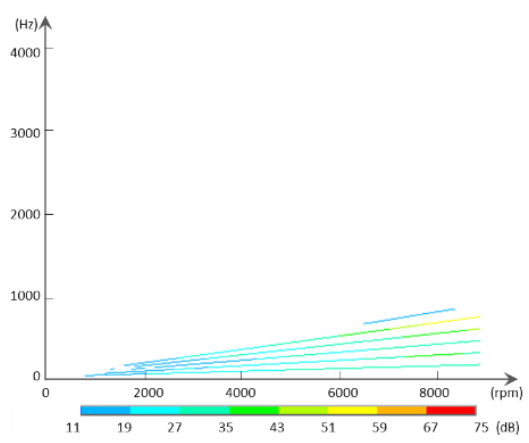

(d)
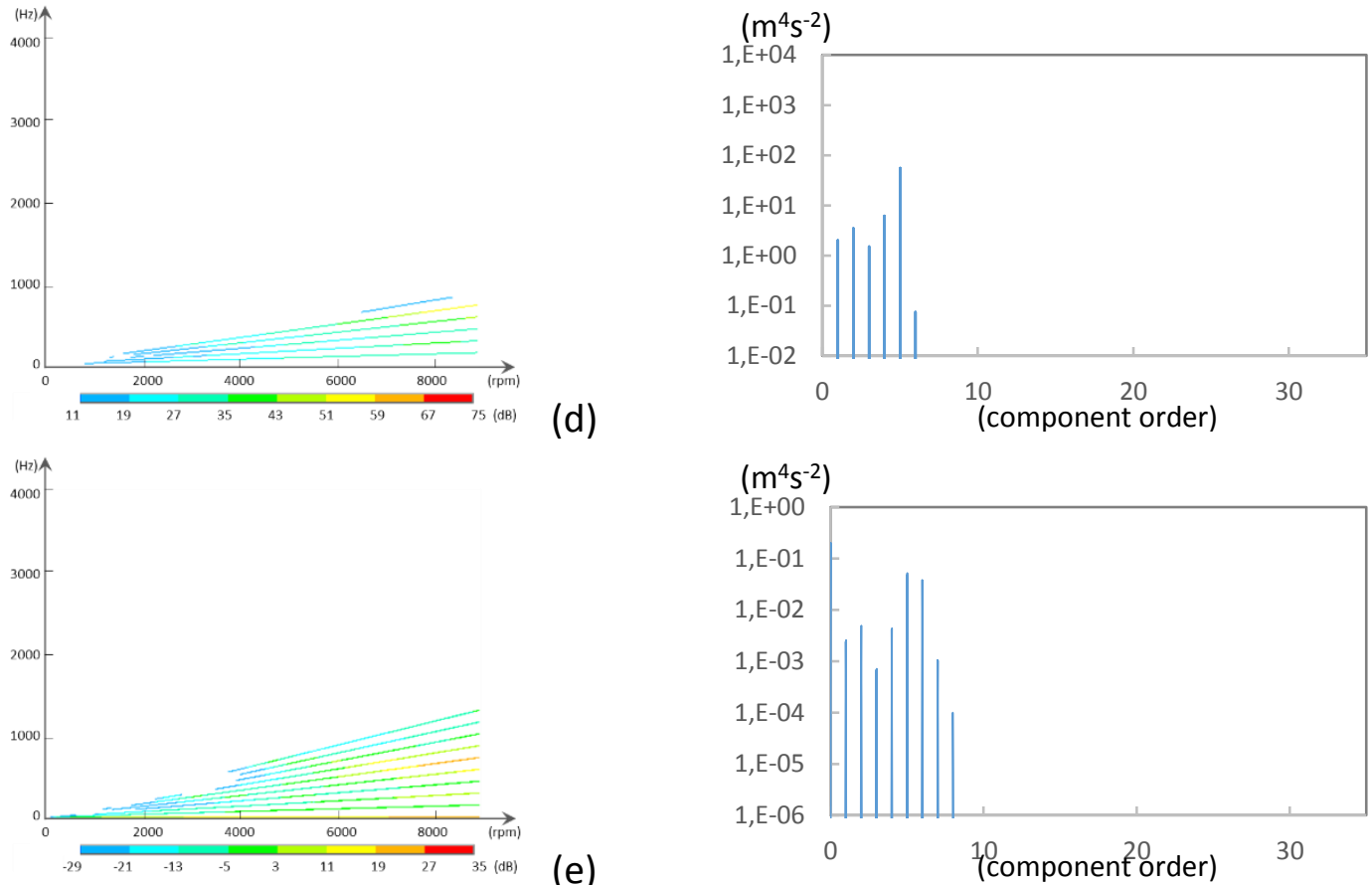

(e)

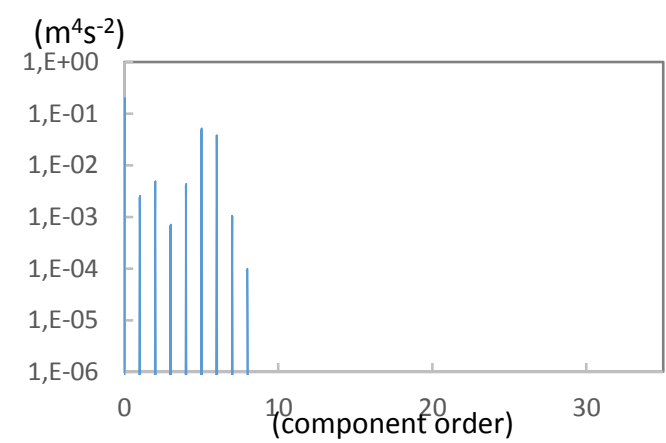

(i)

Figure 6: Spectrograms of the mean square velocity $L_{S V^{2}}(d B)$ in the range $[0-8500 \mathrm{rpm}]$. Amplitude spectra of $\left.S<\overline{V^{2}(\omega)}\right\rangle_{S}$ for the standard operating regime (6000 rpm). 


\section{Conclusion}

The vibroacoustic response of an electric window-lift gear motor is predicted. Excitation sources considered are electromagnetic normal forces and input torque fluctuation, rotor mechanical imbalance, worm gear static transmission error and mesh stiffness fluctuation and gear wheel eccentricity. The spectrograms of the dynamic response show components corresponding to the harmonics of the excitation spectra: $\mathrm{H}_{1 / 73}$ for the gear wheel eccentricity, $\mathrm{H}_{1}$ for the mechanical imbalance, Hi for the static transmission error, $\mathrm{H}_{10 \times \mathrm{i}}$ for the electromagnetic normal forces and the input torque fluctuation. The coupling between the mesh stiffness fluctuation and the other excitation sources results in a change in the amplitude of the harmonics $\mathrm{H}_{\mathrm{i}}$ and generates a frequency enrichment of the dynamic response characterized by lateral components around harmonics $\mathrm{Hi}$ and harmonics $\mathrm{H}_{10 \mathrm{xi}}$. They contribute little to the overall vibroacoustic response level but they may have a significant impact on the quality of noise radiated directly by the gear motor or indirectly by the supporting structure to which forces are transmitted at the fixation points. For the standard stationary operating conditions, the weight of the electromagnetic normal forces, the rotor mechanical imbalance and the worm gear static transmission error to the spatial average of the mean square velocity of the gear motor are of the same order of magnitude when a A-weighting is used. These sources lead to a radiated sound power level of the order of $55 \mathrm{~dB}$ in good agreement with the experimental measurements. Torque fluctuations and the gear wheel eccentricity are secondary sources. On the other hand, the gear wheel eccentricity generates a high amplitude force transmitted to the supporting structure of at very low frequency, which adds to the transmitted force generated in an equivalent manner by the electromagnetic normal forces, the mechanical imbalance and the static transmission error.

A collaborative work with the car manufacturers would make possible to calculate the transmitted forces not by considering the embedded fixation points but taking into account the mechanical impedance of the supporting structure. Furthermore, the predictive calculation of the vibroacoustic behavior of the door could be useful to evaluate the overall noise generated in the passenger compartment by the gear motor.

\section{Acknowledgment}

The authors thank the LabCom LADAGE (Laboratoire de Dynamique des engrenAGEs) sponsored by the program ANR-14-LAB6-0003 and the Labex CeLyA (Centre Acoustique Lyonnais).

\section{References}

[1] Xut M. Marangoni R. Vibration analysis of a motor-flexible coupling-rotor system subject to misalignment and unbalance. Part 1: Theoretical model analysis. Part 2: Experimental validation. Journal of sound and vibration. 176(5), 663-691, 1994.

[2] Welbourn D.B. Fundamental Knowledge of Gear Noise - A Survey. Conference on Noise and Vibrations of Engines and Transmissions. Cranfield Institute of Technology. C177/79, 9-29, 1979.

[3] Rigaud E., Barday, D. Modelling and analysis of static transmission error. 4th World Congress on Gearing and Power Transmission, Paris, 1961-1972, 1999.

[4] Rigaud E., Sabot J., Perret-Liaudet J. Comprehensive approach for the vibrational response analysis of a gearbox. Revue européenne des éléments finis, 9, (1-3), 315-330, 2000.

[5] Perret-Liaudet J. An original method for computing the response of a parametrically excited forced system. Journal of Sound and Vibration, 196(2), 165-177, 1996. 